\title{
Genetic Variability, Heritability, Genetic Advance and Trait Associations in Selected Sorghum (Sorghum Bicolor L. Moench) Accessions in Ethiopia
}

\author{
Tsegau Senbetay* ${ }^{*}$ Tegegn Belete \\ Ethiopian Institute of Agricultural Research/Jimma Agricultural Research Center,; P.O.B: 192, Jimma ,Ethiopia
}

\begin{abstract}
Genetic variability can be defined as the genetic makeup of organisms within a population change. The objective of this study aims to analyze and determine the traits having greater interrelationship with grain yield utilizing the correlation and path analysis and to estimate the genetic variations, heritability and expected genetic advance in the selected sorghum accessions. The experiment was conducted in 2017 planting season in Jimma Agricultural research station during the main season and row column design was used with two replications. 84 introduced sorghum accessions were evaluated in this experiment and the analysis of variance exhibited there was a significant variation among the genotypes for the traits studied. Plant height, head weight, grain yield, rust, days to fifty percent flowering displayed high heritability. Moreover, these traits also have high genetic advance and high genotypic coefficient of variation. The correlation analysis revealed that grain yield displayed positive and significant genetic correlation with number of heads per plot, head weight per plot, days to fifty percent flowering, days to maturity. However, negative genetic correlation with plant aspect, bird damage, grain mold 1,2,3 (1-5 grain mold score) within ten days interval. Thus, number of heads per plot, head weight per plot, plant height, panicle length and panicle width are most important yield contributing traits. Therefore, selection based on these traits studied is important and effective for plant breeding. The path analysis revealed that plant height and panicle length displayed significant and positive direct effect on grain yield. However, head weight per plot, number of heads per plot and panicle width exhibited negative and significant indirect effect with grain yield. This revealed that there is wide range of genetic variability among the genotypes used for all of the traits tested. Therefore, it is important to know this high genetic variability for farther breeding program. In addition to this, high heritability $\left(\mathrm{H}^{2}\right)$ and high genetic advance (GA) are also important for the improvement of the traits through plant breeding (selection). Keywords: Heritability, genetic variance, phenotypic variance, genetic advance, path analysis, phenotypic and genotypic coefficient of variation
\end{abstract}

DOI: $10.7176 / \mathrm{JBAH} / 10-12-01$

Publication date:June $30^{\text {th }} 2020$

\section{Introduction}

Sorghum [Sorghum bicolour (L.) Moench] is one of the important cereal crops in the world, which is grown in Africa, Asia, USA, Australia and Latin America. It is the fourth most important cereal crop following rice, wheat, maize and staple food in the same central parts of the world. Worldwide, it is cultivated on 41.07 million ha area with production of 58.42 million tons in the year approx., 2019-20 (Anonymous 2019a). It is the fifth most important staple food crop after wheat, rice, maize and barley (FAOSTAT) (2012).

Wortmann et al. (2006) reported that drought, low soil fertility (nutrient deficiencies), insect stem borers, insect shoot fly, quelea birds, Striga and weeds were recognized as major production constraints affecting sorghum in eastern Africa. Although these constraints cause significant grain yield loss, the relative importance varies from region to region, within and among the countries. For example, shoot fly is reported to cause significant grain loss in Ethiopia and Uganda, but is of less importance in Mozambique (Wortmann et al. 2006). In Ethiopia, drought and Striga weed have been found to be the most important constraints in the northern and north-eastern parts of the country (Gebretsadik et al. 2014). Other research has shown that moisture stress during grain filling can be the most important constraint in Ethiopia (Simane et al. 1998).

Genetic diversity analysis of sorghum germplasm is fundamental for breeding and conservation strategies. To stabilize sorghum production in Ethiopia, identification of superior cultivars in terms of yield and resistance to biotic and abiotic factor is of major importance. Identification of genotypes with desirable traits and their subsequent use in breeding and establishment of suitable selection criteria can be helpful for successful varietal improvement programs. Analysis of variability among the traits and the association of a particular character with other traits contributing to yield of a crop would be of great importance in planning a successful breeding program (Mary and Gopalan; 2006).

In planning sorghum improvement program, knowledge of variability of traits could be a key to the success. Comparative variability of traits is evaluated by estimating the genotypic coefficient of variation (GVC) and the phenotypic coefficient of variation (PCV) (Ahmad et al; 2011). According to Sami et al. [2013], heritable genetic effects and non-heritable environmental effects contribute to variability found in germplasm. The GCV expresses 
the heritable portion, while the PCV is an expression of both the genetic and environmental effects on the trait (Bello et al; 2007). In sorghum, several studies on genetic variation have been documented. In a study of genetic variation, Warkad et al. [2008] reported high genotypic and phenotypic coefficient of variation for yield and yield related traits in sorghum germplasm. Dhutmal et al. [2014] also reported high genotypic and phenotypic coefficient of variation for grain yield and its components in drought-tolerant sorghum. It has been observed that the estimates of genetic variance were smaller than their respective phenotypic variances (Khan et al; 2005).

Grain yield is complex trait, depend on many attributes characters. Yield potential accompanied with desirable combination of traits has always been the major objective of sorghum breeding program. Correlation measures the level of dependence traits and out of numerous correlation coefficients it is often difficult to determine the actual mutual effects among traits [Ikanovic et al; 2011]. The estimates of correlations alone may be often misleading due to mutual cancellation of component traits. So, it becomes necessary to study path coefficient analysis, which takes in to account the casual relationship in addition to degree of relationship [Mahajan et al, 2011]. The path coefficient analysis initially suggested by Wright [Wright et al, 1921] and described by Dewey and $\mathrm{Lu}$ [1959] allows partitioning of correlation coefficient into direct and indirect contributions (effects) of various traits towards dependent variable and thus helps in assessing the cause-effect relationship as well as effective selection. Path analysis is necessary for better understanding of correlations among traits, which is a pathway for knowledge on specificity of the genetic material being studied. Ikanovic [2010] concluded that even if correlation values are similar for certain pairs of traits, direct effects for some of them and especially indirect effects via other traits can differ for some traits.

Therefore, this study aims to analyze and determine the traits having greater interrelationship with grain yield utilizing the correlation and path analysis and to estimate the genetic variations, heritability and expected genetic advance in the selected sorghum varieties.

\section{Materials and methods}

The experiment was laid out in Jimma Agricultural Research Center in 2017 planting season. Eight four sorghum accessions were collected/introduced from perdue University/USA for the project sorghum and millet innovation lab. Row column design with two replication was used; with row and plant spacing of 75 and $15 \mathrm{~cm}$ respectively. The plots were fertilized with a basal application of Diammonium Phosphate (DAP) at 100kg ha-1 and top dressing was carried out with urea (100kg ha-1) before earting up at 30 days after emergency as recommended.

The phenotypic, genotypic and environmental variance for individual location was computed according to the formula proposed by Singh and Chaudhury (1999) as follows:

$\sigma^{2} \mathrm{~g}=\frac{m s g-m s e}{r}$

$\sigma^{2} \mathrm{e}=\mathrm{MSE}$

$\sigma 2 \mathrm{p}=\frac{\sigma 2 g+\sigma 2 e}{r}$

Where, $\mathrm{Msg}=$ mean squares due to genotype, $\mathrm{MSE}=$ mean squares of error (environmental variance or mean square of the residual), $\mathrm{r}=$ the number of replications, $\sigma 2 \mathrm{e}=$ random error variance, $\sigma 2 \mathrm{~g}=$ genotypic variance and $\sigma 2 p=$ phenotypic variance. Based on the analysis of variance, the phenotypic coefficient of variation (PCV), genotypic coefficient of variation (GCV), broad sense heritability and genetic advance (GA) were estimated as using formula by Burton and Devane (1953) as follows:

$\mathrm{GCV}=\frac{\sqrt{\sigma 2 g}}{G M} X 100 \% ; \mathrm{PCV}=\frac{\sqrt{\sigma 2 p}}{G M} X 100 \% X ; \mathrm{H}^{2}=\frac{\sigma \mathrm{g}}{\sigma p} x 100, \mathrm{GA}=\mathrm{k} \times \quad \sigma 2 \mathrm{p} \mathrm{x} \mathrm{H} \mathrm{H}^{2 ; \mathrm{GA}}$ as percent of mean $=(\mathrm{GAM})=A=\frac{G A}{G M} X 100$ Where; $\overline{\mathrm{x}} / \mathrm{GM}=$ phenotypic trait population (grand mean). GA is genetic advance; is a constant $=20.06$ at $5 \%$ selection intensity; Estimation of broad sense heritability $\left(\mathrm{H}^{2}\right)$ and genetic advance as percent of mean (GAM) assuming selection intensity of 5\% for individual and combined analysis of variance were computed using the formula adopted from (Johnson et al., 1955). $\mathrm{H}^{2}$ was classified according to (Robinson et al., 1949) as follows: 0 $-30 \%=$ low $30-60 \%=$ moderate; $>60 \%$ and GAM: $0-10 \%=$ low $; 10-20 \%=$ medium, greater than $20 \%$. Different data were taken, such as grain yield, plant height, panicle length, panicle/head weight, plant aspect and other important traits. Data for all these attributes were subjected to analysis of variance according to Steel and Torrie [1980] to evaluate the significant differences among the genotypes. Estimation of variation components and phenotypic correlations were calculated as suggested by Burton [1952], Wright [1960, 1968] and Narasimharao and Rachie [1964]. The correlation coefficient was partitioned into direct and indirect causes according to Dewey and $\mathrm{Lu}$ [1959] and Turner and Stevens [1959]. Test of significance was carried out with (n-2) degree of freedom for phenotypic correlation by referring to the table given by Snedecor and Cochran [1989].

\section{Result and Discussion}

The analysis of variance shown that there was highly significant $(\mathrm{P}=0.01)$ difference among the genotypes. Grain yield ranged from $5 \mathrm{qt} /$ ha to $48 \mathrm{qt} /$ ha, plant height ranged $90.8 \mathrm{~cm}$ to $322.2 \mathrm{~cm}$, days to flowering ranged from 112 to 65 and days to maturity ranged from 141 to 164 days. These variations between genotypes in all studied traits 
may be due to genetic combinations with environmental factors which were suitable for one genotype than other. Tag El-Din et al (2012) reported highly significant mean squares for plant height, grain yield per plant, panicle length, panicle width, 1000 seed weight, days to $50 \%$ flowering and number of kernels per head. Moreover, Jimmy et al (2017) revealed similar results such as significant mean squares for plant height, grain yield, panicle length, panicle width, 100 seed weight, and days to $50 \%$ flowering.

Genotypic variance ranged from 0.45 in bird damage to 6243 in plant height and phenotypic variance ranged from 0.65 in rust to 6512.2 in plant height. High genotypic and phenotypic variance indicated that there is wide genetic variation among the genotypes. Which implies that quantitative traits such as plant height, head weight, grain yield and panicle length have high phenotypic and genotypic variance that indicates high additive gene action for the inheritance of these traits studied. Genotypic variance is one of the genetic parameters that determine effectiveness of selection process in plant breeding program (Sleper \& Poehlman, 2006). Genetic advance ranged from 91.96 in bird damage to $213045.2 \%$ in plant height.

Genotypic and phenotypic correlation coefficients between the various morphological, yield attributing traits computed are presented in table 3. Genotypic correlation coefficient provides measures of genetic association between traits and thus helps to identify the more important as well as less important traits to be considered in breeding programs.

Phenotypic coefficient of variation ranged from 59.4 bird damage $\%$ to $627.47 \%$ in plant height and genotypic coefficient of variation ranged from $4.37 \%$ in days to flowering to $130.18 \%$ for root lodge. Moreover, heritability ranged from $43.1 \%$ in panicle length to $95.87 \%$ in plant height, which displayed the highest heritability in plant height and the minimum heritability in panicle width. Jimmy et al (2017) revealed that, GCV ranged from 7.21 in days to flowering $\%$ to $36.02 \%$ in number of harvestable tillers, PCV ranged from $7.39 \%$ in days to $50 \%$ flowering to $59.34 \%$ number of harvestable tillers, heritability ranged from 73 for panicle length to $99 \%$ for plant height in sorghum accessions. Grain yield per plant was found positively and significantly correlated with initial plant count, ear head length, 100 seed weight and harvest index at both genotypic and phenotypic level in Rabi sorghum (Deshmukh et al., 2018).

Keerthana et al (2019) reported high PCV and GCV in $\mathrm{NA}^{+} / \mathrm{K}^{+}$ratio followed by grain yield. Jawale et al (2019) reported high genetic advance with high heritability for calcium content and iron content in finger millet indicated additive gen action for expression of these characters and selection may be effective in breeding program while selecting genotypes. In addition to this Turi et al (2007) revealed higher phenotypic coefficient of variation than genotypic coefficient of variation for plant height, days to $50 \%$ tasseling, days to $50 \%$ silking, ear height, cob length and days to maturity in maize, which represents higher degree of interaction of genotypes with environment.

The effectiveness of selection for any trait depends on the extent of genetic variability. Heritability of a trait is prerequisite, as it provides the extent of genetic control for expression of trait. Similar findings reported that maximum heritability recorded for days to flowering $(96.3 \%)$ and fresh weight per plant $(93.5 \%)$, whereas, panicle width (63.6\%) revealed minimum estimate for heritability (Khandelwal et al., 2015). Moreover, he also displayed high heritability for days to flowering, days to maturity and panicle length with low genetic advance, indicating that these traits are controlled by non-additive gene action.

The association of high heritability with high genetic advance and GCV was reported in case of fresh weight per plant and leaf area, indicating the presence of additive gene action and consequently a high genetic gain from phenotypic selection. Moreover, days to flowering, days to maturity and panicle length showed high heritability with low genetic advance (Table 1.), indicating that these traits are controlled by non-additive gene action (Khandelwal et al., 2015) . Delaying of leaf senescence (stay green) is an effective strategy for increasing of crop yield, particularly under water-limited conditions (Rachmadi, 2015) and Study of genotypic variance of stay green is very useful for breeding program of stay green character. Moreover, Kandel et al (2018) reported that there was a significant and positive phenotypic coefficient of variation in silk receptivity, shelling percentage, cob length and diameter, number of kernels per ear, number of kernel row per ear, and thousand kernel weight; but significant and negative correlation with tassel blast, anthesis silking interval, leaf area index, leaf firing under heat stress condition in maize genotypes. 
Table 1. ANOVA skeleton of yield and yield components

\begin{tabular}{llllll}
\hline Source of variation & Tms & Ems & LSD (5\%) & CV (\%) & GM \\
\hline AN & $1.81 * *$ & 0.54 & 1.457 & 22.6 & 3.24 \\
DF & $155.08^{* *}$ & 11.97 & 6.882 & 4 & 87.35 \\
DM & $73.19 \mathrm{~ns}$ & 57.19 & 15.041 & 4.9 & 152.87 \\
GM1 & $0.77 * *$ & 0.18 & 0.851 & 30 & 1.43 \\
Gm2 & $1.97 * *$ & 0.33 & 1.1467 & 24.2 & 2.38 \\
GM3 & $1.22^{* *}$ & 0.4 & 1.2588 & 35.2 & 1.8 \\
NH & $732.70^{* *}$ & 190 & 27.41 & 21.2 & 64.9 \\
BD & $0.56 * *$ & 0.22 & 0.9294 & 24.8 & 1.88 \\
dscr & $0.99 * *$ & 0.32 & 1.1265 & 27.3 & 2.08 \\
gy & $519 * *$ & 115.7 & 1283.6 & 39.8 & 27.02 \\
hwt & $1087.8 * *$ & 107.2 & 1235.6 & 23.6 & 43.8 \\
pas & $2.14 * *$ & 0.38 & 1.2212 & 18.9 & 3.24 \\
ph & $6377.6 * *$ & 269.2 & 32.64 & 9.9 & 165.4 \\
pl & $56.64 * *$ & 27.11 & 10.356 & 22.4 & 23.28 \\
pw & $2.23 n s$ & 1.77 & 2.647 & 21 & 6.33 \\
rl & $8.99^{* *}$ & 6.13 & 4.923 & 132.4 & 1.87 \\
sl & $15.68^{*}$ & 6.85 & 5.206 & 85.4 & 3.07 \\
rust & $0.61 *$ & 0.09 & 0.5969 & 17.3 & 1.73 \\
scnt & $193.5^{* *}$ & 83.6 & 18.186 & 19.6 & 46.66 \\
\hline
\end{tabular}

Tms $=$ treatment mean square, ems=error mean square, $\mathrm{CV}(\%)=$ coefficient of variation, $\mathrm{GM}=$ grain mold

Table 2. Mean of genotypic variance, phenotypic variance, and genotypic coefficient of variation, phenotypic coefficient of variation, heritability and genetic advance

\begin{tabular}{lllllll}
\hline Source of variation & QGV & QPV & GCV & PCV & H2 & GA \\
\hline AN & 1.54 & 2.08 & 38.36 & 80.12 & 74.16 & 317.24 \\
DF & 149.1 & 161.07 & 13.98 & 135.79 & 92.57 & 30713.57 \\
DM & 44.6 & 101.79 & 4.37 & 81.6 & 43.81 & 9186.57 \\
GM1 & 0.68 & 0.86 & 57.91 & 77.88 & 78.83 & 140.46 \\
Gm2 & 1.8 & 2.13 & 56.31 & 94.62 & 84.43 & 371.21 \\
GM3 & 1.02 & 1.42 & 56.03 & 88.73 & 71.71 & 209.1 \\
NH & 637.7 & 827.7 & 38.91 & 357.12 & 77.04 & 131366.2 \\
BD & 0.45 & 0.66 & 35.46 & 59.4 & 67.15 & 91.96 \\
dscr & 0.83 & 1.15 & 43.88 & 74.45 & 72.14 & 171.08 \\
gy & 461.15 & 576.85 & 79.48 & 462.05 & 79.94 & 94996.9 \\
hwt & 1034.2 & 1141.4 & 73.42 & 510.48 & 90.61 & 213045.2 \\
pas & 1.95 & 2.33 & 43.13 & 84.81 & 83.83 & 402.61 \\
ph & 6243 & 6512.2 & 47.77 & 627.47 & 95.87 & 1286058 \\
pl & 43.09 & 70.2 & 28.2 & 173.64 & 61.38 & 8875.51 \\
pw & 1.34 & 3.11 & 18.3 & 70.12 & 43.1 & 276.35 \\
rl & 5.93 & 12.05 & 130.18 & 253.86 & 49.18 & 1220.86 \\
sl & 12.26 & 19.11 & 114.03 & 249.47 & 64.15 & 2524.74 \\
rust & 0.56 & 0.65 & 43.31 & 61.39 & 86.2 & 115.93 \\
scnt & 151.72 & 235.32 & 26.4 & 224.57 & 64.47 & 31254.32 \\
\hline
\end{tabular}

Where; $\mathrm{AN}=$ anthrac nose, $\mathrm{DF}=$ days to flowering, $\mathrm{DM}=$ days to maturity=GM1=grain mold one, GM2= grain mold two, $\mathrm{GM} 3=$ grain mold three, $\mathrm{NH}=$ number of heads, $\mathrm{BD}=$ bird damage $=$ dscr= disease score, gy $=$ grain yield, hwt=head weight, pas=plant aspect, $\mathrm{ph}=$ plant height, $\mathrm{pl}=$ panicle length, $\mathrm{pw}=$ panicle width, $\mathrm{rl}=$ root length, $\mathrm{sl}=$ stem lodge, scnt=stand count at harvest.

The phenotypic and genotypic correlation coefficients are presented in 3 table 4 and respectively. Genotypic correlation coefficient provides an estimate of inherent association between two traits. Correlation coefficient helps in determining the direction of selection and number of characters to be considered in improving the grain yield. So it is a matter of great importance to the plant breeders to find out of the characters correlated with yield and also how they are associated among themselves. Grain yield revealed significant and positive association with plant height, panicle length, and days to $50 \%$ flowering, days to maturity, number of harvestable heads per plot and number of heads, head weight per plot of genetic correlation. However, there is negative association with rust, anthracnose, disease score, bird damage, plant aspect, stand count, stem lodge and grain mold 1, 2, 3 ( grain mold 1-5 score with 10 days interval) (Table 4). Grain yield displayed positive and strong genotypic correlation $\left(\mathrm{r}=0.92^{* *}\right)$ with head weight. It also has positive genotypic correlation $(\mathrm{r}=0.42 * *)$ with days to $50 \%$ flowering, 
$0.35 * *$ with days to maturity.

Khodarahmpour and Choukan, (2011) reported similar finding in a study of fifteen inbred line under heat stress condition reported that grain yield had positive and significant correlation with number of kernel ear , number of kernel row , 1000-grain weight, and cob diameter. Kaur et al., (2010) reported similar result significant negative association leaf firing and tassel blast with grain yield under heat stress. Cairnset et al.,(2012) reported significant correlation between grain yield and ASI and SPAD reading was negatively correlated. Krasensky, J., and Jonak, C. (2012) reported similar result for significant positive for association between chlorophyll content and grain yield under drought stress.

The path coefficient analysis (Table 5) revealed that plant height, panicle length, grain mold two (gm2), anthracnose, bird damage and stand count at harvest, displayed positive and significant direct effect on grain yield (6.66), (111), (6.66), (3.33.67), (2.498) and (1.56) respectively. But negative direct effect was displayed with the other traits listed in table 5. However, days to maturity (-4.4), grain mold one (-2), panicle width (-7), grain mold three (-4.44089), rust (-2.42861), root lodge (-5.6), stem lodge (-111022), disease score (-6.10623), number of heads per plot (-6.73073) and head weight per plot (-8.88178) displayed negative but significant direct effect with grain yield. Positive indirect of days to flowering was through plant height (2.42), grain mold score one (2.4), grain mold three (8.59401), rust (4.21073), stem lodge (2.02094), disease score (2.4509) and number of heads per plot (2.13087). Indirect effect of days to maturity was through plant height (2.62), panicle length (1.59), panicle width (6.3), grain mold one (4.6), grain mold three (1.35), disease score (2.5855) and stand count (6.4). Plant height displayed positive indirect effect through panicle length (4.88), grain mold one (11), grain mold three (2.70348), rust (7.15409), disease score (2.88177), and stand count (3.45). However, plant height exhibited negative but significant indirect effect through panicle width (-6), grain mold two (-3.7), anthracnose (-2.35445), root lodge (-2.4), stem lodge (-2.019961), number of heads per plot (-1.19134) and head weight per plot (-5.34497). Number of heads per plot displayed positive and significant indirect effect through plant height (1.18), panicle length (1.31) and panicle width (8.6). Moreover, head weight displayed positive and significant indirect effect through plant height (4.01), panicle length (8.97) and panicle width (6.2). Tag El-Din et al (2012) reported low but significant direct of panicle length with grain yield. But he reported positive indirect effect of panicle length was through plant height, days to $50 \%$ flowering, 100-kernel weight, leaf area and leaf number. Wankhede et al. (1985), Patil and Thombre (1995) showed positive direct effect of panicle length on grain yield. Veerabadbiran et al. (1994) stated that number of grains/panicle had the highest positive effect on grain yield. Similar results were obtained by Mahajan et al. (2011), who found that panicle length and number of grains per panicle has positive direct effect on grain yield/ panicle. Therefore, those traits like number of heads per plot, panicle length, head weight, plant height and rust had greater importance. Hence, due consideration should be given to these characters, while planning a breeding strategy for increased grain yield.

Table 3. Phenotypic correlation of yield and yield related traits of sorghum accessions

\begin{tabular}{|c|c|c|c|c|c|c|c|c|c|c|c|c|c|c|c|c|c|c|c|}
\hline & Df & $\mathrm{dm}$ & $\mathrm{ph}$ & $\mathrm{pl}$ & pw & $\mathrm{gm} 1$ & $\mathrm{gm} 2$ & $\operatorname{gm} 3$ & $\mathrm{AN}$ & Rust & $\mathrm{R} 1$ & $\mathrm{~s} 1$ & pas & bd & dscr & scnt & $\mathrm{NH}$ & hwt & gy \\
\hline df & 1.00 & & & & & & & & & & & & & & & & & & \\
\hline $\mathrm{dm}$ & 0.19 & 1.00 & & & & & & & & & & & & & & & & & \\
\hline $\mathrm{ph}$ & 0.32 & 0.27 & 1.00 & & & & & & & & & & & & & & & & \\
\hline $\mathrm{pl}$ & -0.05 & 0.12 & 0.04 & 1.00 & & & & & & & & & & & & & & & \\
\hline $\mathrm{pw}$ & -0.01 & -0.05 & 0.08 & 0.45 & 1.00 & & & & & & & & & & & & & & \\
\hline gm1 & 0.00 & -0.17 & -0.43 & -0.07 & -0.11 & 1.00 & & & & & & & & & & & & & \\
\hline $\mathrm{gm} 2$ & -0.25 & -0.13 & -0.48 & 0.03 & 0.04 & 0.55 & 1.00 & & & & & & & & & & & & \\
\hline $\operatorname{gm} 3$ & -0.13 & -0.21 & -0.51 & -0.03 & -0.07 & 0.72 & 0.62 & 1.00 & & & & & & & & & & & \\
\hline AN & -0.25 & -0.23 & -0.07 & 0.03 & 0.09 & -0.08 & 0.12 & -0.02 & 1.00 & & & & & & & & & & \\
\hline rust & -0.18 & -0.17 & -0.26 & -0.13 & -0.11 & 0.11 & 0.18 & 0.17 & -0.31 & 1.00 & & & & & & & & & \\
\hline $\mathrm{rl}$ & 0.03 & 0.11 & 0.34 & -0.06 & -0.07 & -0.15 & -0.05 & -0.18 & 0.05 & -0.07 & 1.00 & & & & & & & & \\
\hline s1 & -0.18 & -0.09 & 0.16 & -0.06 & 0.10 & -0.23 & -0.05 & -0.12 & 0.17 & 0.02 & 0.25 & 1.00 & & & & & & & \\
\hline pas & -0.28 & -0.15 & -0.16 & -0.02 & 0.07 & 0.24 & 0.51 & 0.23 & 0.32 & 0.07 & 0.20 & 0.18 & 1.00 & & & & & & \\
\hline bd & -0.24 & -0.14 & -0.44 & -0.06 & -0.15 & 0.27 & 0.43 & 0.35 & 0.12 & 0.30 & -0.06 & 0.05 & 0.36 & 1.00 & & & & & \\
\hline dscr & -0.34 & -0.22 & -0.38 & -0.06 & 0.06 & 0.11 & 0.39 & 0.23 & 0.27 & 0.24 & -0.04 & 0.08 & 0.41 & 0.51 & 1.00 & & & & \\
\hline scnt & -0.08 & -0.02 & 0.14 & -0.05 & -0.07 & -0.02 & -0.17 & -0.06 & 0.02 & -0.10 & 0.04 & 0.00 & -0.11 & -0.01 & -0.08 & 1.00 & & & \\
\hline $\mathrm{NH}$ & -0.29 & 0.12 & 0.19 & 0.09 & -0.12 & -0.06 & -0.11 & 0.05 & 0.03 & -0.14 & 0.01 & -0.08 & -0.02 & -0.10 & -0.10 & 0.39 & 1.00 & & \\
\hline hwt & 0.39 & 0.27 & 0.58 & 0.10 & 0.05 & -0.33 & -0.48 & -0.32 & -0.18 & -0.36 & 0.04 & -0.12 & -0.45 & -0.40 & -0.38 & 0.31 & 0.43 & 1.00 & \\
\hline gy & 0.34 & 0.21 & 0.53 & 0.08 & 0.06 & -0.32 & -0.49 & -0.36 & -0.15 & -0.30 & 0.04 & -0.11 & -0.46 & -0.42 & -0.40 & 0.28 & 0.37 & 0.86 & 1.00 \\
\hline
\end{tabular}

Where; $\mathrm{df}=$ days to $50 \%$ flowering, $\mathrm{dm}=$ days to maturity, $\mathrm{ph}=$ plant height, $\mathrm{pl}=$ panicle length, $\mathrm{pw}=$ panicle width, gm $1=$ grain mold 1, gm $2=$ grain mold 2 , gm $3=$ grain mold 3 with ten days interval $(1-5$ score $), A N=$ anthracnose, $\mathrm{rl}=$ root lodge, $\mathrm{sl}=$ =stem lodge, pas=plant aspect, $\mathrm{bd}=$ bird damage, dscr=disease score, $\mathrm{scnt}=$ =stand count at harvest, $\mathrm{NH}=$ number of harvestable heads per plot, $\mathrm{hwt}=$ head weight per plot, gy=grain yield 
Table 4. Genotypic Correlation of yield and yield related traits of sorghum accessions

\begin{tabular}{|c|c|c|c|c|c|c|c|c|c|c|c|c|c|c|c|c|c|c|c|}
\hline & Df & $\mathrm{dm}$ & ph & $\mathrm{pl}$ & $\mathrm{pw}$ & gm1 & gm2 & $\mathrm{gm} 3$ & AN & rust & $\mathrm{rl}$ & sl & pas & bd & $\mathrm{dscr}$ & scnt & $\mathrm{NH}$ & hwt & gy \\
\hline $\mathrm{df}$ & 1.00 & & & & & & & & & & & & & & & & & & \\
\hline $\mathrm{dm}$ & 0.27 & 1.00 & & & & & & & & & & & & & & & & & \\
\hline $\mathrm{ph}$ & 0.36 & 0.39 & 1.00 & & & & & & & & & & & & & & & & \\
\hline $\mathrm{pl}$ & -0.04 & 0.14 & 0.04 & 1.00 & & & & & & & & & & & & & & & \\
\hline $\mathrm{pw}$ & 0.01 & -0.09 & 0.08 & 0.53 & 1.00 & & & & & & & & & & & & & & \\
\hline gm1 & -0.01 & -0.21 & -0.49 & -0.08 & -0.14 & 1.00 & & & & & & & & & & & & & \\
\hline $\mathrm{gm} 2$ & -0.30 & -0.19 & -0.56 & -0.02 & -0.02 & 0.63 & 1.00 & & & & & & & & & & & & \\
\hline $\mathrm{gm} 3$ & -0.19 & -0.30 & -0.61 & -0.03 & -0.10 & 0.81 & 0.71 & 1.00 & & & & & & & & & & & \\
\hline AN & -0.29 & -0.23 & -0.71 & 0.04 & 0.17 & -0.03 & 0.14 & 0.05 & 1.00 & & & & & & & & & & \\
\hline rust & -0.17 & -0.23 & -0.29 & -0.14 & -0.15 & 0.12 & 0.22 & 0.20 & -0.38 & 1.00 & & & & & & & & & \\
\hline $\mathrm{rl}$ & 0.04 & 0.06 & 0.43 & -0.11 & -0.05 & -0.25 & -0.12 & -0.28 & 0.05 & -0.05 & 1.00 & & & & & & & & \\
\hline $\mathrm{sl}$ & -0.18 & -0.19 & 0.18 & -0.01 & 0.15 & -0.26 & -0.11 & -0.17 & 0.25 & 0.03 & 0.37 & 1.00 & & & & & & & \\
\hline pas & -0.31 & -0.19 & -0.17 & -0.04 & 0.05 & 0.29 & 0.58 & 0.29 & 0.38 & 0.10 & 0.20 & 0.23 & 1.00 & & & & & & \\
\hline bd & -0.28 & -0.25 & -0.52 & -0.07 & -0.14 & 0.38 & 0.57 & 0.53 & 0.13 & 0.36 & -0.07 & 0.02 & 0.48 & 1.00 & & & & & \\
\hline dscr & -0.40 & -0.42 & -0.47 & -0.13 & -0.03 & 0.20 & 0.20 & 0.32 & 0.31 & 0.32 & -0.08 & 0.12 & 0.47 & 0.62 & & & & & \\
\hline scnt & -0.07 & 0.00 & 0.22 & 0.04 & 0.00 & -0.02 & -0.16 & -0.06 & 0.01 & -0.17 & 0.09 & -0.06 & -0.12 & -0.10 & -0.07 & 1.00 & & & \\
\hline $\mathrm{NH}$ & -0.32 & 0.08 & 0.18 & 0.12 & -0.13 & -0.06 & -0.13 & 0.04 & 0.11 & -0.20 & 0.03 & -0.10 & 0.02 & -0.15 & -0.12 & 0.60 & 1.00 & & \\
\hline hwt & 0.46 & 0.32 & 0.60 & 0.08 & -0.01 & -0.34 & -0.57 & -0.38 & -0.22 & -0.43 & 0.08 & -0.17 & -0.50 & -0.51 & -0.52 & 0.44 & 0.41 & 1.00 & \\
\hline gy & 0.42 & 0.35 & 0.57 & 0.06 & 0.00 & -0.38 & -0.59 & -0.47 & -0.18 & -0.41 & 0.12 & -0.19 & -0.55 & -0.55 & -0.56 & 0.40 & 0.33 & 0.92 & 1.00 \\
\hline
\end{tabular}

Where; $\mathrm{df}=$ days to $50 \%$ flowering, $\mathrm{dm}=$ days to maturity, $\mathrm{ph}=$ plant height, $\mathrm{pl}=$ panicle length, $\mathrm{pw}=$ panicle width, gm1 $=$ grain mold 1, gm2=grain mold 2 , gm3= grain mold 3 with ten days interval $(1-5$ score $), A N=$ anthracnose, $\mathrm{rl}=$ root lodge, $\mathrm{sl}=$ stem lodge, pas=plant aspect, $\mathrm{bd}=$ bird damage, dscr=disease score, $\mathrm{scnt}=$ stand count at harvest, $\mathrm{NH}=$ number of harvestable heads per plot, hwt=head weight per plot, gy=grain yield

Table 5. Direct (diagonal) and indirect effect of different traits on grain yield (genotypic path coefficent).

\begin{tabular}{|c|c|c|c|c|c|c|c|c|c|c|c|c|c|c|c|c|c|c|}
\hline & df & $\mathrm{dm}$ & ph & $\mathrm{pl}$ & pW & gml & $\mathrm{gm} 2$ & $\mathrm{gm3}$ & an & rust & Il & sl & pas & $\mathrm{bd}$ & dscr & scnt & $\mathrm{NH}$ & hut \\
\hline df & 0 & $-1,2 E-16$ & $2.42 E-16$ & $-4.56-18$ & $-4 E-18$ & $2.4 E-18$ & $-2 E-16$ & 8.59401E-17 & $-9.4984 E-17$ & 4.21073E-17 & $-2,4 E-17$ & 2.02094E-17 & 0 & $-7.02038 E-17$ & $72.4569 \mathrm{E}-16$ & $-1.1 \mathrm{E}-18$ & $2.13687 E-16$ & $-4.10392 E-16$ \\
\hline $\mathrm{dm}$ & 0 & $-4.4 E-16$ & $2.62 E-16$ & $1.59 E-17$ & 6.3E-17 & 4.6E-17 & $-1.3 E-16$ & $1.35132 E-16$ & $-9.71689 E-17$ & 5.6764E-17 & $-3.1 E-17$ & 2.06224E-17 & 0 & $-6.173566-17$ & $72.5855 E-16$ & $6.4 E-20$ & $-5.23583 E-17$ & -2.84901E-16 \\
\hline ph & 0 & $-1.7 E-16$ & $6.66 E-16$ & $4.68 E-18$ & $-6 E-17$ & 1.1E-16 & $-3.78-16$ & $2.70348 E-16$ & $-2.35445-17$ & 7.15469E-17 & $-2.4 E-16$ & $-2.01961 E-17$ & 0 & $-1.307585-16$ & 6 2.88177E-16 & $3.466-18$ & $-1.191348-16$ & -5.344976-16 \\
\hline pl & 0 & $-6.4 E-17$ & $2.81 E-17$ & 1.11E- -16 & $-4 E-16$ & 1.9E-17 & $-1.4 E-17$ & $1.40643 E-17$ & 1.34659E-17 & 3.4836E-17 & $6.29 E-17$ & $1.17462 E-18$ & 0 & $-1.806066-17$ & $78.09666-17$ & $5.655-19$ & -7.96514E-17 & $-7.17471 E-17$ \\
\hline pw & 0 & 4.2E-17 & 5.66E-17 & $5.84 E-17$ & $-78-16$ & $3.2 E-17$ & $-1,6 E-17$ & $4.36318 E-17$ & $5.63982 E-17$ & 3.43584E-17 & $2.88 E-17$ & $-1.6338 E-17$ & 0 & $-3.40453 E-$ & 7 1.90200E-17 & $-5.3 E-20$ & 8.66514E-17 & 8.33111E-18 \\
\hline gml & 0 & $9.188-17$ & $-3.35-16$ & $-9.4 E-18$ & $9.5 E-17$ & $-2 E-16$ & 4.177--16 & $-3.58553 E-16$ & $-1.123435-17$ & $-2.94542 E-17$ & $1.41 E-16$ & $2.88281 E-17$ & 0 & $9.60682 E-17$ & $-1.22631 E-16$ & $6-3.1 E-19$ & $4.08421 E-17$ & $3.00036 E-16$ \\
\hline $\mathrm{gm} 2$ & 0 & $8.366-17$ & $-3.7 E-16$ & $-2.3 E-18$ & $1.6 \mathrm{E}$ & -1E-16 & $6.666-16$ & $-3.171646 E-16$ & 58E-17 & 73E-17 & 17 & 1.24534E-17 & 0 & $1.41319 E-16$ & $-2.726677-16$ & $6-2.5 E-18$ & $8.4787 E-17$ & $5.03819 E-16$ \\
\hline $\mathrm{gm} 3$ & 0 & $1.35 E-16$ & $-4.1 E-16$ & $-3.5 E-18$ & $6.5 E-17$ & $-2 E-16$ & $4.76 E-16$ & $-4,40898-16$ & $1.75793 E-17$ & $-4.94271 E-17$ & 1.54E-16 & $1.84297 E-17$ & 0 & $1.32057 E-16$ & $-1.961388-16$ & $69.822-19$ & $-2.82085 E-17$ & $3.398175-16$ \\
\hline AN & 0 & $1.02 E-16$ & $-4.7 E-16$ & 4.49E-18 & $-1 E-16$ & 7.55-18 & 9.4E-17 & $-2.3439 E-17$ & $3.33067 \mathrm{E}-16$ & 9.29284E-17 & $-2.8 E-17$ & $-2.7861 E-17$ & 0 & $3.36606 E-17$ & $-1.89299 E-16$ & 6 1.52E-19 & $-7.57341 E-17$ & 1.98819E-16 \\
\hline rust & 0 & 1.04E-16 & $-2 E-16$ & $-1.6 E-17$ & $9.8 E-17$ & $-3 E-17$ & $1.45 E-16$ & $-9.0381 E-17$ & $-1.27445 E-16$ & $-2,42861 E-16$ & $3.05 E-17$ & $-3.17191 E-18$ & 0 & $9.07774 E-17$ & $-1.977266-16$ & $6-2.66-18$ & $1.3417 E-16$ & $3.78124 E-16$ \\
\hline Il & 0 & $-2.5 E-17$ & $2.85 E-16$ & $-1.35-17$ & $3.5 E-17$ & $5.66-17$ & $-8.2 E-17$ & 1.22251E-16 & 1.65934E-17 & $1.33234 E-17$ & $-5.6 E-16$ & $-4.05231 E-17$ & 0 & $-1.72437 \mathrm{~F}-17$ & 7 5.12679E-17 & $1.37 F-18$ & - $2.27976-17$ & $-7.52465 E-17$ \\
\hline sl & 0 & $8.25 E-17$ & 1.21E-16 & $-1,2 E-18$ & $-1 E-16$ & $5.8 E-17$ & $-7.55-17$ & 7.37188E-17 & 8.35831E-17 & $-6.93855 E-18$ & $-2 E-16$ & $-1.110022 E-16$ & 0 & $5.89029 E-18$ & $-7.469755-17$ & - $-9.7 E-19$ & $6.934 E-17$ & 1.47704E-16 \\
\hline pas & 0 & $8.39 E-17$ & $-1.2 E-16$ & $-4.2 E-18$ & $-3 E-17$ & $-7 E-17$ & 3.9E-16 & $-1.287155-16$ & $1.27618 E-16$ & $-2.46091 E-17$ & $-1.1 \mathrm{EE}-16$ & $-2.56399 E-17$ & 0 & 1.19162E-16 & $-2.8836 E-16$ & $-1.9 E-18$ & $-1,11124 E-17$ & 4.40581E-16 \\
\hline bd & 0 & 1.1E-16 & $-3.5 E-16$ & $-8 E-18$ & 9.1E-17 & $-9 E-17$ & $3.79 E-16$ & $-2.34768 E-16$ & 4.48808E-17 & $-8.84015 E-17$ & $3.83 E-17$ & $-2.61791 E-18$ & 80 & 2.498E- -16 & $-3.76876 E-16$ & $6-1.55-18$ & $1.027188 E-16$ & $4.53966-16$ \\
\hline dscr & 0 & $1.88 E-16$ & $-3.1 E-16$ & $-1.56-17$ & 2.1E-17 & $-4 E-17$ & $1.34 E-16$ & $-1.42646 E-16$ & $1.03254 E-16$ & $-7.86409 E-17$ & $4.66 E-17$ & $-1.35814 E-17$ & 70 & $1.54177 E-16$ & $-6.10623 E-16$ & $6-1,1 E-18$ & $8.177255-17$ & $4.65645 E-16$ \\
\hline sent & 0 & $-1.8 E-18$ & $1.48 E-16$ & $4.02 E-18$ & $2.3 E-18$ & 4.4E-18 & $-1,1 E-16$ & 2.79243E-17 & 3.25073E-18 & 4.04073E-17 & $-4.9 E-17$ & 6.90892E-18 & 0 & $-2.40533 E-17$ & 7.1754EE-17 & $1.566-17$ & -4.04867E-16 & - -3.931888-16 \\
\hline $\mathrm{NH}$ & 0 & $-3.5 E-17$ & $1.18 E-16$ & $1.31 E-17$ & $8.6 E-17$ & $1.3 E-17$ & $-8.4 E-17$ & $-1.861186-17$ & $3.74767 E-17$ & $4.8412 E-17$ & $-1.9 E-17$ & $1.14375 E-17$ & 0 & $-3.8122 E-17$ & $7.41418 E-17$ & $9.39 E-18$ & $-6.73073 E-16$ & $-3.62705 E-16$ \\
\hline hist & 0 & $-1.4 E-16$ & $4.01 E-16$ & $8.976-18$ & $6.2 E-18$ & $7.5 E-17$ & $-3.8 E-16$ & 1.69909E-16 & $-7.4557 E-17$ & $1.03393 E-16$ & $-4.7 E-17$ & $1.8463 E-17$ & 0 & $-1.27678 E-16$ & 6 3.20131E-16 & $6.91 E-18$ & 3. $-2,74863 E-16$ & $=-8.88178=-16$ \\
\hline
\end{tabular}

Where; $\mathrm{df}=$ days to $50 \%$ flowering, $\mathrm{dm}=$ days to maturity, $\mathrm{ph}=$ plant height, $\mathrm{pl}=$ panicle length, $\mathrm{pw}=$ panicle width, gm $1=$ grain mold 1, gm $2=$ grain mold 2 , gm $3=$ grain mold 3 with ten days interval $(1-5 \mathrm{score}), \mathrm{AN}=$ anthracnose, $\mathrm{rl}=$ root lodge, $\mathrm{sl}=$ stem lodge, pas=plant aspect, $\mathrm{bd}=$ bird damage, $\mathrm{dscr}=$ disease score, $\mathrm{scnt}=$ stand count at harvest, $\mathrm{NH}=$ number of harvestable heads per plot, hwt=head weight per plot, gy=grain yield

\section{Conclusion and Recommendation}

The analysis of variance displayed that there is a significant difference among the genotypes for all of the traits studied. This revealed that there is wide range of genetic variability among the genotypes used for all of the traits tested. Therefore, it is important to know this high genetic variability for farther breeding program. In addition to this, high heritability $\left(\mathrm{H}^{2}\right)$ and high genetic advance (GA) are also important for the improvement of the traits through plant breeding (selection). Plant height, head weight, grain yield, rust, days to fifty percent flowering displayed high heritability. Moreover, these traits also have high genetic advance and high genotypic coefficient of variation. The correlation analysis revealed that grain yield displayed positive and significant genetic correlation with number of heads per plot, head weight per plot, days to fifty percent flowering, days to maturity. However, 
negative genetic correlation with plant aspect, bird damage, grain mold 1, 2, 3 (1-5 grain mold score) within ten days interval. Thus, number of heads per plot, head weight per plot, plant height, and panicle length and panicle width are most important yield contributing traits. Therefore, selection based on these traits studied is important and effective for plant breeding. The path analysis revealed that plant height and panicle length displayed significant and positive direct effect on grain yield. However, head weight per plot, number of heads per plot and panicle width exhibited negative and significant indirect effect with grain yield. Therefore, understanding the direct and indirect of the studied traits is also important for genetic improvement of crops in plant breeding.

\section{Acknowledgment}

We authors thanks to sorghum and millet innovation lab (SMIL) project for their financial support. We thanks also to Jimma Agricultural Research Center for financial and other materials support. Great thanks also goes to cereal case team members of Jimma research center for their every support, starting from planting to data collection, especially to Ato kedir Aba gisa (Technical assistant). The last but not the least our gratitude goes to Mr Alamir Ayenew for his support in data analysis.

\section{Reference}

Anonymous. World Agricultural production, 2019a, 21.

Burton, G.W., 1952. Quantitative inheritance in grasses. Proceedings of the 6 International Grassland Congress, 1: 227-283.

Cairns, J. E., Sonder, K., Zaidi, P. H., Verhulst, N., Mahuku, G., Babu, R., and Rashid, Z. (2012). Maize Production in a Changing Climate: Impacts, Adaptation, and Mitigation Strategies. Advances in agronomy, 114 (1).

D. Bello, A. M. Kadams, S. Y. Simon, and D. S. Mashi, "Studies on genetic variability in cultivated sorghum (Sorghum bicolor L. Moench) cultivars of Adamawa State Nigeria," American-Euriasian Journal Agricultural Enviroment Science, vol. 2, no. 3, pp. 297-302, 2007.

Deshmukh, S. B., A. B. Bagade, and A. K. Choudhari. "Correlation and path analysis studies among rabi sorghum (Sorghum bicolor L. Moench) mutants." Int. J. Curr. Microbiol. App. Sci 6 (2018): 1014-1020.

Dewey, D.R. and K.H. Lu, 1959. A correlation and path coefficient analysis of components of crested wheatgrass seed production. Agron. J., 51: 515-518.

Dewey, D.R. and K.H. Lu, 1959. A correlation and path coefficient analysis of components of crested wheatgrass seed production. Agron. J., 51: 515-518.

FAO. Database of agricultural production. FAO Statistical Databases (FAOSTAT) (2012).

Gebretsadik R, Shimelis H, Laing MD, Tongoona P, Mandefro N. 2014. A diagnostic appraisal of the sorghum farming system and breeding priorities in Striga infested agro-ecologies of Ethiopia. Agricultural Systems 123: 54-61.

Ikanovic, J., 2010. Genotypic and phenotypic specificity of sorghum varieties, Sudan grass and their interspecific hybrids. Ph.D Thesis, Faculty of Agriculture in Belgrade, Belgrade University, New York

Ikanovic, J., J. Djordje, M. Radojka, P. Vera, Dejan, Panicle width S. Marija and R.Sveto, 2011. Path analysis of productive traits in sorghum species. Genetika, 43(2): 253-262.

Jimmy, M. L., F. Nzuve, O. Flourence, E. Manyasa, and J. Muthomi. "Genetic variability, heritability, genetic advance and trait correlations in selected sorghum (Sorghum bicolor L. Moench) varieties." Int. J. Agron. Agri. R 5 (2017): 47-56.

Kandel, Manoj, Surya Kant Ghimire, Bishnu Raj Ojha, and Jiban Shrestha. "Correlation and path coefficient analysis for grain yield and its attributing traits of maize inbred lines (Zea mays L.) under heat stress condition." International Journal of Agriculture, Environment and Food Sciences 2, no. 4 (2018): 124-130.

Kaur, R., Saxena, V. K., and Malhi, N. S. (2010).Combining ability for heat tolerance traits in spring maize (zea mays L.). Maydica, 55(3): 195.

Keerthana, K., S. Chitra, A. Subramanian, S. Nithila, and M. Elangovan. "Studies on genetic variability in finger millet [Eleusine coracana (L.) Gaertn] genotypes under sodic conditions." Electronic Journal of Plant Breeding 10, no. 2 (2019): 566-569.

Khandelwal, V., M. Shukla, B. S. Jodha, V. S. Nathawat, and S. K. Dashora. "Genetic parameters and character association in sorghum (Sorghum bicolor (L.) Moench)." Indian Journal of Science and Technology 8, no. 22 (2015): $2-4$

Khodarahmpour, Z., and Choukan, R. (2011). Genetic Variation of Maize (Zea mays L.) Inbred Lines in Heat Stress Condition. Seed and Plant Improvment Journal, 27(4): 539-554.

Krasensky, J., and Jonak, C. (2012).Drought, salt, and temperature stressinduced metabolic rearrangements and regulatory networks. Journal of experimental botany, 63(4):1593-1608.

M. Q. Khan, S. I. Awan, and M. M. Mughal, "Estimation of genetic parameters in spring wheat genotypes under rainfed conditions," Industrial Journal of Biological Sciences, vol. 2, no. 3, pp. 367-370, 2005.

Mahajan, R.C., P.B. Wadikar, S.P. Pole and M.V. Dhuppe, 2011. Variability, correlation and path analysis studies 
in sorghum. Research Journal of Agricultural Sciences, 2(1): 101-103.

Mahajan, R.C., P.B. Wadikar, S.P. Pole and M.V. Dhuppe, 2011. Variability, correlation and path analysis studies in sorghum. Research Journal of Agricultural Sciences, 2(1): 101-103.

Narasimharao, D.V. and K.O. Rachie, 1964. Correlations and heritability of morphological characters in grain sorghum. Madras Agric. J., 51: 156-161.

R. A. Sami, M. Y. Yeye, M. F. Ishiyaku, and I. S. Usman, "Heritability studies in some sweet sorghum (Sorghum Bicolor. L. Moench) genotypes," Journal of Biology Agriculture and Healthcare, vol. 3, no. 17, pp. 49-51, 2013.

R. R. Dhutmal, S. P. Mehetre, A. W. More, H. V. Kalpande, A. G. Mundhe, and A. J. Sayyad Abubakkar, "Variabity parameters in rabi sorghum (sorghum bicolor L. Moench) drought tolerent genotypes," The BioScan, vol. 9, no. 4, pp. 1455-1458, 2014.

Rachmadi, Meddy. "PHENOTYPIC AND GENOTYPIC VARIANCE AND HERITABILITY OF STAY GREEN CHARACTER AMONG 22 ELITE SORGHUM (Sorghum bicolor (L.) Moench) GENOTYPES." KnE Life Sciences (2015): 318-325.

S. Q. Ahmad, S. Khan, M. Ghaffar, and F. Ahmad, "Genetic diversity analysis for yield and other parameters in maize (Zea mays L.) Genotypes,” Asian Journal of Agricultural Sciences, vol. 3, no. 5, pp. 385-388, 2011.

S. S. Mary and A. Gopalan, "Dissection of genetic attributes yield traits of fodder cowpea in F3 and F4," Journal of Applied Sceneces Research, vol. 2, pp. 805-808, 2006.

Simane B, Wortmann CWS, Hoogenboom G. 1998. Haricot bean agro-ecology in Ethiopia: definition using agroclimatic and crop growth simulation models. African Crop Science Journal 6: 9-18.

Sleper, D.A and J.M. Poehlman. 2006. Breeding Field Crops. Fourth Edition. Blackwell Publishing. 345-366.

Steel, R.G.D. and J.H. Torrie, 1980. Principles and Procedures of Statistics. McGraw Hill Book.

Tag El-Din, A. A., Eatemad M. Hessein, and E. A. Ali. "Path coefficient and correlation assessment of yield and yield associated traits in sorghum (Sorghum bicolor L.) Genotypes." American-Eurasian Journal of Agricultural \& Environmental Sciences 12, no. 6 (2012): 815-819.

Tag El-Din, A.A., Hessein, E.M. and Ali, E.A., 2012. Path coefficient and correlation assessment of yield and yield associated traits in sorghum (Sorghum bicolor L.) genotypes. American-Eurasian Journal of Agricultural \& Environmental Sciences, 12(6), pp.815-819

Turi, Naushad Ali, S. Salim Shah, Sajid Ali, H. Rahman, Tahir Ali, and Muhammad Sajjad. "Genetic variability for yield parameters in maize (Zea mays L.) Genotypes." J. Agric. Biol. Sci 2, no. 4-5 (2007): 1-3.

Turner, M.E. and C.D. Stevens, 1959. The Regression Analysis of Casual path. Biometrics, 15: 236-250. Snedecor, G.W. and W.G. Cochran, 1989. Statistical Methods. 8 Editions. The Iowa State University.

Veerabadhiran, P., S. Palanisamy and G.A. Samy 1994. Association analysis in grain sorghum. Madras Agriculture Journal, 81(10): 532-534.

Wankhede, M.G., V.B. Shekhar and P.W. Khorgade, 1985. Variability, correlation and path analysis studies in sorghum (Sorghum bicolor L.). PKV Research Journal, 9(2): 1-5. . Patil, R.C. and M.V. Thombre, 1995. Yield components and their implications for selection in sorghum. Journal of Maharashtra Agricultural University, 10(1): 43-46.

Wortmann CS, Mamo M, Mburu C, Letayo E, Abebe G, Kayuki KC, Chisi M, Mativavarira M, Xerinda S, Ndacyayisenga T. 2006. Atlas of sorghum (Sorghum bicolor (L.) Moench) production in eastern and southern Africa. Lincoln, NE: University of Nebraska-Lincoln.

Wright, S., 1921. Systems of Mating. Genetics, 6: 111-178.

Wright, S., 1960. Path Coefficient and Path Regression: Alternative or Complementary Concepts? Biometrics, 16: 189-202.

Wright, S., 1968. Evaluation and the Genetics of Population1. Genetics and Biometrics Foundations. The University of Chicago.

Y. N. Warkad, N. R. Potdukhe, A. M. Dethe, P. A. Kahate, and R. R. Kotgire, "Genetic variability, heritability and genetic advance for quantitative traits in sorghum germplasm," Agricultural Science Digest, vol. 28, no. 3, pp. 165-169, 2008 . 